UNIVERSITÀ DEGLI STUDI DI ROMA "LA SAPIENZA" DIPARTIMENTO DI ECONOMIA PUBBLICA

Working Paper No. 76

Alessandro Girardi and Paolo Paesani

NET FOREIGN ASSETS IN THE EURO AREA: A COINTEGRATION ANALYSIS 


\begin{abstract}
This paper discusses the macroeconomics of NFA at the Euro Area level, making use of the cointegrated VAR methodology. The wish to contribute to the literature on EMU motivates the choice of the topic; the non-stationarity of the data explains the choice of the methodology. The main conclusion of the paper is that, as far as Net Foreign Assets are concerned, the use of synthetic Euro area aggregate data yields a series of results consistent with economic theory. Real growth and exchange rate appreciation are both consistent with NFA accumulation. Portfolio adjustment considerations appear also to be important.
\end{abstract}

J.E.L. Classification: C32, C51, F21

Keywords: cointegration, euro area, net foreign assets 


\title{
NET FOREIGN ASSETS IN THE EURO AREA: A COINTEGRATION ANALYSIS*
}

\author{
Alessandro Girardi and Paolo Paesani॰
}

\section{Introduction}

The European Monetary Union (EMU), launched on January $1^{\text {st }} 1999$, can be compared to a complex machine made up of two "new" pieces, the Euro and the European Central Bank (ECB), and many "used" ones (the single countries, the national central banks). Any empirical investigation of the functioning of this machine, either limits itself to post-1999 data, which is unfeasible in a standard quarterly time series framework, or uses pre-1999 data too, collecting them on a country-by-country basis and aggregating them, as if EMU had existed before 1999.

The use of synthetic aggregate data is open to many questions, ranging from the validity of the as if idea to various methodological aspects. Recent contributions to the monetary policy literature, however, (e.g. Agresti Mojon [1], Peersman - Smets [25], Mojon - Peersman [22]) recognize the validity of this expedient to investigate the macroeconomics of EMU. We take the same stand, focusing on Net Foreign Assets (NFA).

\footnotetext{
* The authors would like to thank two anonymous referees for helpful comments and suggestions.

• Department of Public Economics, University of Rome "La Sapienza". E-mail: girardi@uniroma1.it.

•- Department of Public Economics, University of Rome "La Sapienza" and Department of Economics, European University Institute, Florence. E-mail: paolo.paesani@iue.it.
} 
NFA are defined as the difference between the stock of foreign assets (bonds, equity, direct foreign investment, foreign exchange reserves) held by domestic residents and the stock of domestic liabilities held by foreign residents. Lane - Milesi-Ferretti [19] suggest three reasons which make the study NFA worthwhile. First, the level of NFA is a key state variable in many open-economy models of growth and the business cycle. Second, many of the benefits of international financial integration are tied to the gross holdings of foreign assets and liabilities, rather than to capital flows. Third, the level and composition of international investment positions may be important in understanding vulnerability to external shocks, the degree of international risk sharing and the dynamics of current account adjustment. ${ }^{1}$

The NFA literature identifies six stylized facts, valid for industrialized economies. First, the accumulation of NFA tends to be associated with real exchange rate appreciation, which compensated the country's positive (negative) international investment position by inducing a current account deficit (surplus) (Gagnon [11], Lane - Milesi-Ferretti [18]).

Second, relative output per-capita can affect NFA accumulation through several channels (Lane - Milesi-Ferretti [20] p.82). If the domestic marginal product of capital decreases, as the domestic stock of capital increases, home investors will seek out overseas investment opportunities, adding to their NFA. An increase in domestic income may lead to a higher savings rate which, even if temporary, could bring about a permanent improvement in terms of NFA. A positive correlation between relative GDP per-capita and NFA accumulation is also found by the traditional stages-of-

1 See also Kray - Ventura [17] and BUSSIERE - ChOARTAREAS - Driver [5]. 
the-balance-of-payments-hypothesis literature (e.g. Fisher - Frenkel [9]).

Third, NFA accumulation in a country appears to be related with a shrinking differential between the long-term interest rates of that country and those of the rest of the world, via falling risk-premia (Lane - MilesiFerretti [20]). Fourth, Selaive - Tuesta [27], [28] claim that NFA affects both cross-country risk-sharing, via the cost of bond holding, and the uncovered interest parity, via the contribution of NFA to explaining nominal exchange rate movements. Fifth, in a world where Ricardian equivalence does not hold, higher levels of public debt may be associated with falling NFA (Faruqee - Laxton [8]).

Finally, a positive correlation is suggested, between NFA accumulation and aging population. However, the impact of demographic factors on NFA position is not just a function of the youth and old-age dependency ratio but also of other factors, e.g. the age structure of the working age population (Mundell [23]).

The contribution of this paper to the EMU literature is threefold. First, we update Euro area NFA using the same methodology as developed by Lane - Milesi-Ferretti [19]. Second, we analyze the linkages between NFA and a subset of the variables indicated as relevant by the literature (real exchange rates, output per-capita and real interest rates) in a theoretically consistent way. Third, we model NFA linkages in a multivariate time-series framework, the cointegrated VAR model, whereas previous contributions prefer panel or single-equation models.

The structure paper is as follows. In section 2, we discuss the theoretical and methodological framework of the analysis. Estimates are 
discussed in section 3. Section 4 concludes. Appendix 1 contains a detailed description of the data and of the aggregating methodology.

\section{The methodology}

This paper investigates the macroeconomics of NFA at the Euro area level within the statistical framework provided by the Vector Error Correction (VEC) model (Johansen [14]). This class of models offers a way of describing the variation of the data, which associates the economic concept of long-run to the statistical concept of stationarity.

The VEC model is especially conceived to analyze integrated time series, taking into account the possibility of linearly combining them to form stationary (cointegration) vectors. Ideally, these vectors describe steady-state configurations, which the data tend to revert to in the long run. Their number and structure are identified on the basis of appropriate statistical tests. Usually, considerable emphasis is placed on the idea that the identification of the cointegration vectors should be theoretically consistent. As Pagan [24] points out, close adherence between statistical procedure and economic theory makes a good compromise between the theoreticallybiased DSGE approach (e.g. Smets - Wouters [29]) and the empiricallybiased approached based on large scale macroeconomic models (e.g. Fagan

- Henry - Mestre [7]).

A theoretical framework for long-run macro-modelling

We consider an open economy consisting of two sectors, domestic and 
foreign, and four markets: output, domestic money, domestic bonds and foreign bonds. The properties of this model have been studied, among others, by Godley [13] and Garratt - Lee - Pesaran - Shin [12]. Private wealth accumulation depends on public finance and balance of payments stock/flow identities and on the relative yields of the different financial instruments (portfolio selection mechanism).

The model contains three blocks. The first block identifies a global technological trend linking domestic $(y)$ and world $(y w)$ real GDP percapita (Binder - Pesaran [3]), sharing the same neoclassical technology. Adding an error term $\mu_{G D P}$, this equilibrium condition reads as

$$
y-y w=\mu_{G D P}
$$

The second block contains the interest and exchange rate parities. These are the Uncovered Interest Parity (parity between domestic and foreign interest rate, UIP), the Fisher Interest Parity (parity between domestic interest rate and inflation, FIP), the Purchasing Power Parity (parity between domestic and foreign price level expressed in the same currency, PPP) and the Term Structure parity (parity between domestic short and long-term interest rate, TERM). The empirical literature recognizes that these parities may not hold in their strong form because of market sluggishness and imperfections (see Juselius - MacDonald [16]).

We take the same stand-point, assuming the existence of two "mixed" parities: an internal parity and external one. The "internal" parity mixes up TERM, FIP and PPP linking the short-term real interest rate ( $r s$ ), the longterm real interest rate $(r l)$ and the real exchange rate $(q)$. This condition may be written as 


$$
(r l-r s)+\beta_{1} \cdot q+\beta_{2} \cdot r s=\mu_{Y C}
$$

where $\beta_{1} \leq 0, \beta_{2} \geq 0$ and $\mu_{G D P}$ indicates the deviation from the equilibrium condition.

The "external" parity condition mixes FIP and UIP and links the domestic $(r l)$ and foreign ( $r l w)$ real interest rate. Including the deviation term $\mu_{U I P}$, it can be written as

$$
r l-r l w=\mu_{U I P}
$$

The last block describes how agents allocate their wealth among domestic money and domestic and foreign securities. As a result of this choice, the net external position of the private sector $(n f a)$ emerges as a function of domestic GDP-per capita, real interest rates and the real exchange rate. Domestic determinants of $n f a$ are linked to foreign variables through the two conditions 1 and 3.

$$
n f a+\beta_{3} \cdot q+\beta_{4} \cdot r l+\beta_{5} \cdot r s+\beta_{6} \cdot y=\mu_{N F A}
$$

where $\beta_{3} \geq 0, \beta_{4} \geq 0, \beta_{5} \leq 0, \beta_{6} \leq 0$, reflect some of the stylized facts mentioned above, and $\mu_{N F A}$ indicates the deviation from the equilibrium condition.

\section{Econometric framework}

Adopting the same notation as introduced above, the VEC model, forming the basis of our investigation, may be written as follows 


$$
\left[\begin{array}{l}
\Delta q_{t} \\
\Delta y w_{t} \\
\Delta r l w_{t} \\
\Delta r l_{t} \\
\Delta r s_{t} \\
\Delta y_{t} \\
\Delta n f a_{t}
\end{array}\right]=\mathbf{a}+\sum_{j=1}^{m-1} \boldsymbol{\Gamma}_{j} \cdot\left[\begin{array}{l}
\Delta q_{t-j} \\
\Delta y w_{t-j} \\
\Delta r l w_{t-j} \\
\Delta r l_{t-j} \\
\Delta r s_{t-j} \\
\Delta y_{t-j} \\
\Delta n f a_{t-j}
\end{array}\right]+\boldsymbol{\Pi} \cdot\left[\begin{array}{l}
q_{t-1} \\
y w_{t-1} \\
r l w_{t-1} \\
r l_{t-1} \\
r s_{t-1} \\
y_{t-1} \\
n f a_{t-1}
\end{array}\right]+\mathbf{\Phi} \cdot \mathbf{d}_{t}+\mathbf{u}_{t}
$$

with $\mathbf{u}_{t} \sim N\left(\mathbf{0}, \boldsymbol{\Sigma}_{u}\right)$.

Estimating (5) requires taking three steps. First, the lag length $m$ and the deterministic component $\mathbf{d}_{t}$ are chosen so that estimated residuals match the multi-normal distribution as closely as possible, this being an essential requirement for a correct statistical inference.

Second, the long-term component of the model is identified, evaluating the degree of consistency between the data and the theoretical framework discussed above. The number of cointegrating vectors is equal to the (reduced) rank of the matrix $\boldsymbol{\Pi}$ and is determined on the basis of two tests: the trace test and the maximum eigenvalue test (Johansen [15]). Being of reduced rank, II can be expressed as the product of two matrices of rank $r<k$, i.e. as $\boldsymbol{\Pi}=\mathbf{A} \cdot \mathbf{B}^{\prime}$. Matrix $\mathbf{B}$ contains the $r<k$ cointegration vectors. Matrix A contains the feedback coefficients (loadings).

Checking the theoretical consistency of the data implies testing the following cointegration structure is 


$$
\left[\begin{array}{lllllll}
0 & -1 & 0 & 0 & 0 & 1 & 0 \\
\beta_{1} & 0 & 0 & 1 & \beta_{2} & 0 & 0 \\
0 & 0 & -1 & 1 & 0 & 0 & 0 \\
\beta_{3} & 0 & 0 & \beta_{4} & \beta_{5} & \beta_{6} & 1
\end{array}\right] \cdot\left[\begin{array}{l}
q_{t} \\
y w_{t} \\
r l w_{t} \\
r l_{t} \\
r s_{t} \\
y_{t} \\
n f a_{t}
\end{array}\right]=\left[\begin{array}{l}
\mu_{G D P, t} \\
\mu_{Y C, t} \\
\mu_{U I P, t} \\
\mu_{N F A, t}
\end{array}\right]
$$

Finally, the structural dynamics of the system are identified on the basis of the statistical significance of the parameters collected in the matrices $\mathbf{A}, \boldsymbol{\Gamma}_{j}$ and $\boldsymbol{\Phi}$. Given that impulse response functions may be influenced by the presence of statistically insignificant coefficients, we estimate a parsimonious VECM (Subset VECM), deleting those parameters with $t$-values lower than 2.00. This follows the Sequential Elimination of the Regressors Testing Procedure (SER/TP) proposed by Brüggemann Lütkepohl [4]. The possibility of simultaneous relationships between the variables is taken account of by checking for the statistical significance of the corresponding parameters.

\section{Empirical analysis}

\section{Model specification}

Our data sets consists of 92 quarterly observation ranging from 1980: $q 1$ to 2002: $q 4$ and covering the whole post-oil shock EMS-EMU period. Appendix 1 contains a full description of the data and the aggregating 
methodology.

The lag-length is chosen on the basis of the usual optimal lag-length criteria. Akaike information criterion (AIC) suggests choosing lag 3, while Hannan and Quinn (HQ) and Bayesian (BIC) criteria suggest lag 1. Likelihood-based system reduction tests $[\operatorname{LR}(p / p-1)$ and $\operatorname{LR}(p m a x / p)]$ support our choice of lag 3 (indicated in the upper section of table 1).

The deterministic component includes constant, seasonal dummies, and four impulse dummies $(\ldots 0,0,1,0,0, \ldots)$, all unrestricted with respect to the cointegration space. The impulse dummies refer to the following quarters: 1985:q3 (Plaza agreements), 1990:q1 (German unification), 1992:q3 (EMS crisis), 1999:q1 (launching of third phase of EMU).

Misspecification tests indicate an adequate fit of the chosen specification to the data. Estimated residuals match the multi-normal distribution (lower section of table 1) in a satisfactory way. Chow tests for parameter stability (available on request) do not indicate the presence of significant instability at the system level. ${ }^{2}$

2 Details on both kinds of tests may be found in DOORNIK - HENDRY [6]. 


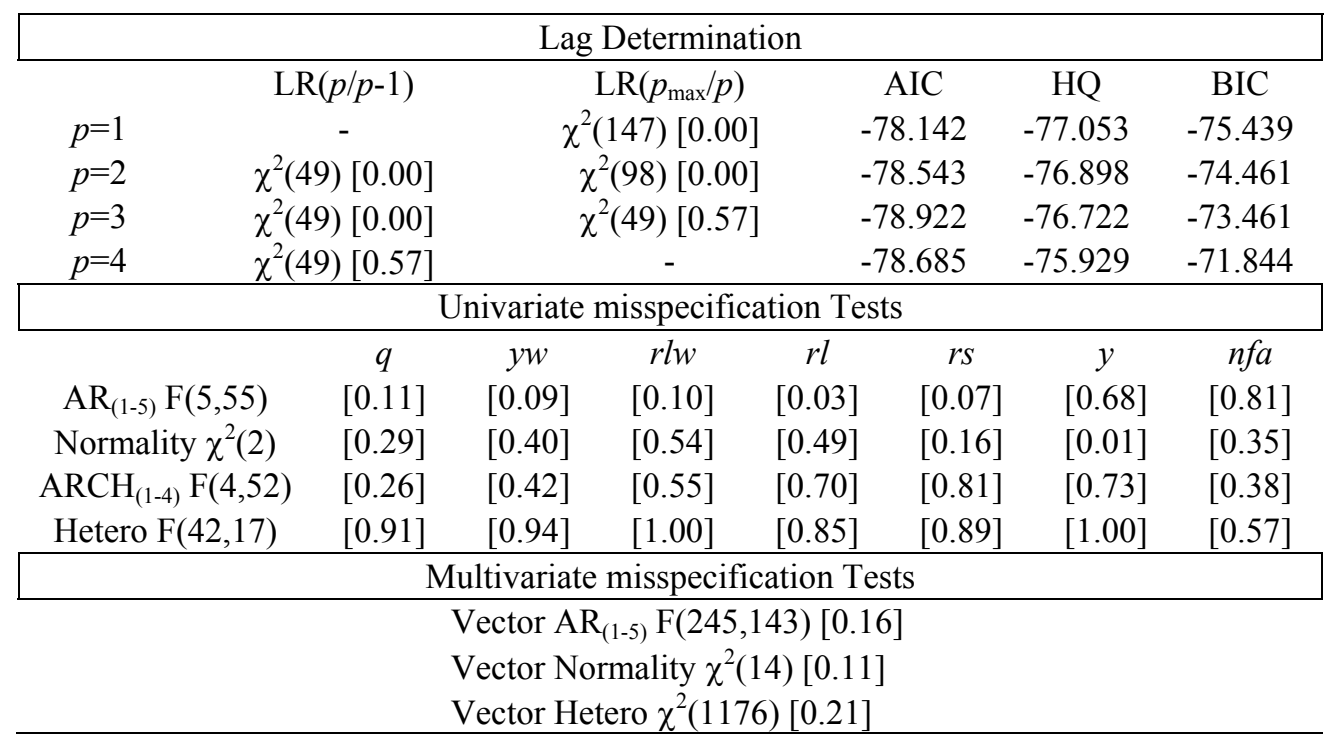

Table 1. Upper part: lag determination. Lower part: model specification tests. p-values in square brackets.

\section{Long-run analysis}

Both the trace and the maximum eigenvalue test suggest choosing rank 4 for the $\Pi$ matrix (table 2, upper part). This conclusion is robust to the inclusion of impulse dummies. ${ }^{3}$

The lower part of table 2 reports the main statistical properties of each time-series within the cointegration space. Stationarity tests are consistent with the assumption that all the variables are not $I(0)$. Excludability tests indicate that none of the variables can be excluded from the cointegration space if not at the loss of useful information. The real exchange rate and

3 Moreover, the number of cointegration relationships is coherent with the economic priors suggested by the theoretical model of reference. Even if this piece of information does not come from statistical procedures, it can turn out useful to determine the dimension of the cointegration space, as suggested by Juselius and Hendry (2001). 
world GDP per capita appear to be weakly exogenous with respect to the long-run parameters of the model. This means it would be possible to specify a subset model conditioning on these two variables.

\begin{tabular}{|c|c|c|c|c|c|c|c|}
\hline \multicolumn{8}{|c|}{ Rank Determination } \\
\hline Eigenvalues & Rank & \multicolumn{3}{|c|}{ Max Eigenvalue Test } & \multicolumn{3}{|c|}{ Trace Test } \\
\hline 0.46 & 0 & & 54.16 & [0.004] & 190.82 & & {$[0.000]$} \\
\hline 0.40 & 1 & & 45.98 & {$[0.007]$} & 136.66 & & {$[0.000]$} \\
\hline 0.37 & 2 & & 40.45 & {$[0.005]$} & 90.68 & & {$[0.000]$} \\
\hline 0.29 & 3 & & 30.46 & {$[0.018]$} & 50.23 & & [0.028] \\
\hline 0.14 & 4 & & 13.67 & {$[0.407]$} & 19.76 & & [0.450] \\
\hline 0.06 & 5 & & 5.67 & {$[0.660]$} & 6.09 & & [0.689] \\
\hline 0.00 & 6 & & 0.42 & {$[0.518]$} & 0.42 & & {$[0.518]$} \\
\hline \multicolumn{8}{|c|}{ Preliminary Analyses on Cointegration Space } \\
\hline Stationarity $\chi^{2}(3)$ & $\begin{array}{c}q \\
{[0.00]}\end{array}$ & $\begin{array}{c}y w \\
{[0.00]}\end{array}$ & $\begin{array}{c}r l w \\
{[0.00]}\end{array}$ & $\begin{array}{c}r l \\
{[0.00]}\end{array}$ & $\begin{array}{c}R s \\
{[0.00]}\end{array}$ & $\begin{array}{c}y \\
{[0.00]}\end{array}$ & $\begin{array}{c}n f a \\
{[0.00]}\end{array}$ \\
\hline Weak Ex. $\chi^{2}(4)$ & [0.39] & [0.12] & {$[0.00]$} & {$[0.00]$} & {$[0.00]$} & [0.04] & [0.03] \\
\hline Exclusion $\chi^{2}(4)$ & {$[0.00]$} & {$[0.00]$} & {$[0.00]$} & {$[0.00]$} & {$[0.00]$} & {$[0.00]$} & {$[0.03]$} \\
\hline
\end{tabular}

Table 2. Determination of the cointegration rank. p-values in square brackets.

Table 3 contains the specification of the cointegration space. This is fully consistent with the theoretical model outlined above. Such specification is not rejected by the data with a p-value of 0.05 (asymptotic LR test) and of 0.43 (parametric bootstrap LR test). ${ }^{4}$

4 We have performed the bootstrap exercise using 4.999 replications. For each replication an artificial dataset, of the same length as the original one (89 observation), is generated, using the observed pre-sample values (over the quarters 1980:1-1980:3) of each variable, the estimated model and a set of random innovations (drawn from a multivariate normal distribution). 


\begin{tabular}{|c|c|c|c|c|c|c|c|}
\hline & $q$ & $y w$ & $r l w$ & $r l$ & $R s$ & $y$ & $n f a$ \\
\hline \multirow{2}{*}{ First vector } & . & -1 & . & . & - & 1 & . \\
\hline & . & . & . & . & . & . & . \\
\hline \multirow{2}{*}{ Second vector } & 0.0317 & . & . & 1 & -0.2714 & . & . \\
\hline & $(0.0043)$ & . & . & . & $(0.0991)$ & . & . \\
\hline \multirow{2}{*}{ Third vector } & $\cdot$ & . & -1 & 1 & . & . & . \\
\hline & . & . & . & . & . & . & . \\
\hline \multirow{3}{*}{ Fourth vector } & 0.5460 & . & . & 19.341 & -19.341 & -0.3368 & 1 \\
\hline & $(0.0791)$ & . & . & . & $(3.3048)$ & $(0.0537)$ & . \\
\hline & \multicolumn{2}{|c|}{$\chi^{2}(7)=13.92$} & \multicolumn{3}{|c|}{\begin{tabular}{cc}
\multicolumn{2}{c}{ Asymptotic C.V. } \\
$5 \%=14.07 \quad 10 \%=$
\end{tabular}} & \multicolumn{2}{|c|}{ Bootstrap C.V. } \\
\hline
\end{tabular}

Table 3. Long-run structure. Standard errors in round brackets.

The first vector links the domestic and world GDP per-capita in a way consistent with the presence of a global technological trend driving both series. The second vector is coherent with the internal parity story. Rewriting it as $(r l-r s)+0.73 \cdot r s+0.0317 \cdot q$, the spread between the two interest rates tends to fall when the short-term interest rate increases and/or when the real exchange rate appreciates. The third vector conforms with the external parity. The fourth vector links NFA, domestic GDP per-capita, the real exchange rate and the differential between the two interest rates. NFA accumulation matches higher GDP-per capita and real exchange appreciation. A relatively higher long-term interest rate with respect to its short-term counterpart appears to be correlated with lower NFA. This might reflect funds flowing back the Euro Area, when domestic long-term lending conditions become more severe. ${ }^{5}$

5 Testing each vector singularly we obtain the following results: first vector ( $\mathrm{p}$-value $=0.38$ ), second vector $(p$-value $=0.26)$, third vector $(p$-value $=0.05)$, fourth vector $(p$-value $=0.21)$. 


\section{Short-run structural analysis}

Table 4 reports the correlation matrix of the reduced-form residuals calculated on the basis of model estimated above. The contemporaneous correlation between $r l$ and $r s$ is very high (0.90) and might reflect the presence of low barriers to capital movements between the money and bond market of the euro area.

\begin{tabular}{cccccccc}
\hline & $q$ & $y w$ & $r l w$ & $r l$ & $r s$ & $y$ & $n f a$ \\
$q$ & 1.0000 &. &. &. &. &. &. \\
$y w$ & 0.3459 & 1.0000 &. &. &. &. &. \\
$r l w$ & -0.2064 & -0.0349 & 1.0000 &. &. &. &. \\
$r l$ & -0.2807 & -0.0400 & 0.4465 & 1.0000 &. &. &. \\
$r s$ & -0.2230 & -0.0959 & 0.2075 & $\mathbf{0 . 8 9 6 7}$ & 1.0000 &. &. \\
$y$ & 0.2837 & 0.4682 & 0.0203 & 0.0299 & 0.0132 & 1.0000 &. \\
$n f a$ & -0.0834 & -0.0538 & 0.1126 & -0.0350 & -0.0834 & 0.1014 & 1.0000 \\
\hline
\end{tabular}

Table 4. Residuals correlation, reduced form model

The possibility of a non diagonal $\boldsymbol{\Sigma}_{u}$ matrix calls the problem of structural identification into question. We address it by re-estimating a parsimonious VECM by 3SLS, allowing the two domestic interest rates to contemporaneously adjust to one another. ${ }^{6}$ Diagnostic tests on the structural model show no evidence of autocorrelation or non-normality of estimated residuals. The p-value associated to the Portmanteau autocorrelation test is equal to 0.33 . The $\mathrm{p}$-value associated to the multivariate normality test is equal to 0.24 . Table 5 reports the coefficients measuring the speed to which the data tend to revert to the long-run equilibrium.

6 All other contemporaneous effects are tested to be borderline statistically not significant. The impact of $\Delta r l$ on $\Delta r s$ is equal to 0.66 (t-value 6.2) while that of $\Delta r s$ on $\Delta r l$ is equal to 0.56 ( $t$-value $3.5)$. 


\begin{tabular}{cccccccc}
\hline & $\Delta q$ & $\Delta y w$ & $\Delta r l w$ & $\Delta r l$ & $\Delta r s$ & $\Delta y$ & $\Delta n f a$ \\
\hline \hline$\mu_{G D P}(-1)$ &. & 0.061 &. &. &. & -0.205 & 0.036 \\
$\mu_{Y C}(-1)$ & -3.479 & $(0.024)$ &. &. &. & $(0.050)$ & $(0.016)$ \\
$\mu_{U I P}(-1)$ & $(0.904)$ &. & -0.495 & -0.203 &. &. & 0.392 \\
$\mu_{N F A}(-1)$ &. &. & 0.185 & -0.128 &. & -0.501 &. \\
&. &. & $(0.066)$ & $(0.030)$ &. & $(0.149)$ &. \\
\hline
\end{tabular}

Table 5. Feedback coefficients. Standard errors in round brackets.

Domestic, world GDP per capita and the NFA/GDP ratio significantly adjust to the first cointegration vector. This is consistent with the common technological trend story and with real growth leading to NFA accumulation. The adjustment to the second cointegration vector (labelled internal parity) affects all the variables of the system with the exception of two GDP series. Adjustment to the external parity affects the two long-term interest rates, consistently with the error correction mechanism, and domestic GDP (IS effect). Finally adjustment to the fourth vector involves the domestic short-term interest rate and the foreign interest rate. The coefficient measuring the adjustment of $\Delta n f a(-0.006)$, is consistent with the error correction mechanism but statistically not significant. This might reflect the fact that deviations from the fourth cointegrating vectors are not strong enough to modify the accumulated stock of NFA. ${ }^{7}$

Finding an exhaustive explanation for all effects of lagged variable

7 Weak exogeneity test and the specification of the adjustment matrix for the estimated Subset VEC model produce non-concordant results with respect to the statistical significant of the adjustment to the cointegration space in the real exchange rate equation and in the world output equation. This may be due to the automatic-sequential procedure we have adopted. We have preferred to leave these two feedback coefficients in the model (instead of deleting them) to preserve the consistency of our modelling approach. 
and deterministic components, reported in table 6 and 7 is both difficult and unnecessary for the purposes of the present study.

As a general consideration, all the lagged and deterministic variables play a statistically significant role in at least one of the equations of the structural model. This corroborates the chosen specification. Lagged interest rates are closely related to one another and affect all the other variables of the system. The real exchange rate reacts to lagged values of the two longterm interest rates and GDP. NFA tend to decrease with real exchange rate depreciation, consistently with the stylized facts discussed above, and react in a non trivial way to the lagged values of the other variables of the model.

\begin{tabular}{|c|c|c|c|c|c|c|c|}
\hline & $\Delta q$ & $\Delta y w$ & $\Delta r l w$ & $\Delta r l$ & $\Delta r s$ & $\Delta y$ & $\Delta n f a$ \\
\hline constant & $\begin{array}{c}0.033 \\
(0.011)\end{array}$ & $\begin{array}{c}0.002 \\
(0.000)\end{array}$ & $\begin{array}{c}0.031 \\
(0.008)\end{array}$ & . & $\begin{array}{c}0.021 \\
(0.007)\end{array}$ & . & $\begin{array}{l}-0.003 \\
(0.001)\end{array}$ \\
\hline$s d 1$ & 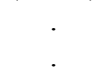 & . & $\begin{array}{c}0.004 \\
(0.001)\end{array}$ & . & $\begin{array}{l}-0.001 \\
(0.000)\end{array}$ & . & $\begin{array}{l}-0.003 \\
(0.001)\end{array}$ \\
\hline$s d 2$ & $\begin{array}{c}0.027 \\
(0.007)\end{array}$ & . & $\begin{array}{l}-0.005 \\
(0.001)\end{array}$ & . & $\begin{array}{l}-0.001 \\
(0.000)\end{array}$ & . & . \\
\hline$s d 3$ & 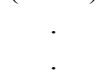 & . & $\begin{array}{c}0.007 \\
(0.002)\end{array}$ & $\begin{array}{c}0.003 \\
(0.000)\end{array}$ & . & . & . \\
\hline di853 & $\cdot$ & . & $\begin{array}{c}0.007 \\
(0.002)\end{array}$ & $\begin{array}{c}0.004 \\
(0.001)\end{array}$ & . & . & . \\
\hline$d i 901$ & . & $\begin{array}{c}0.008 \\
(0.003)\end{array}$ & $\begin{array}{l}-0.006 \\
(0.002)\end{array}$ & . & . & $\begin{array}{c}0.014 \\
(0.007)\end{array}$ & . \\
\hline di923 & $\begin{array}{l}-0.063 \\
(0.022)\end{array}$ & . & . & . & $\begin{array}{c}0.005 \\
(0.002)\end{array}$ & . & $\begin{array}{l}-0.008 \\
(0.002)\end{array}$ \\
\hline di991 & 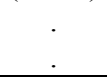 & . & . & . & . & 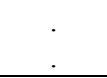 & $\begin{array}{c}0.009 \\
(0.002) \\
\end{array}$ \\
\hline
\end{tabular}

Table 6. Deterministic component. Standard errors in round brackets. 


\begin{tabular}{|c|c|c|c|c|c|c|c|}
\hline & $\Delta q$ & $\Delta y w$ & $\Delta r l w$ & $\Delta r l$ & $\Delta r s$ & $\Delta y$ & $\Delta n f a$ \\
\hline$\Delta q(-1)$ & $\begin{array}{c}0.306 \\
(0.080)\end{array}$ & . & . & . & . & . & $\begin{array}{l}-0.016 \\
(0.008)\end{array}$ \\
\hline$\Delta y w(-1)$ & . & $\begin{array}{c}0.518 \\
(0.072)\end{array}$ & $\begin{array}{l}-0.239 \\
(0.049)\end{array}$ & . & . & . & . \\
\hline$\Delta r l w(-1)$ & ser & . & $\begin{array}{l}-0.287 \\
(0.080)\end{array}$ & . & . & & $\begin{array}{c}0.125 \\
(0.038)\end{array}$ \\
\hline$\Delta r l(-1)$ & $\begin{array}{c}3.213 \\
(0.958)\end{array}$ & . & . & . & $\begin{array}{l}-0.165 \\
(0.074)\end{array}$ & $\begin{array}{c}0.458 \\
(0.211)\end{array}$ & $\begin{array}{l}-0.306 \\
(0.080)\end{array}$ \\
\hline$\Delta r s(-1)$ & . & . & $\begin{array}{c}0.369 \\
(0.086)\end{array}$ & . & . & . & . \\
\hline$\Delta y(-1)$ & . & . & . & . & . & $\begin{array}{c}0.237 \\
(0.076)\end{array}$ & . \\
\hline$\Delta n f a(-1)$ & . & . & . & . & . & . & $\begin{array}{c}0.328 \\
(0.076)\end{array}$ \\
\hline$\Delta q(-2)$ & . & . & . & . & . & . & $\cdot$ \\
\hline$\Delta y w(-2)$ & . & . & $\cdot$ & $\begin{array}{c}0.045 \\
(0.022)\end{array}$ & $\begin{array}{c}0.079 \\
(0.038)\end{array}$ & . & $\begin{array}{c}0.134 \\
(0.058)\end{array}$ \\
\hline$\Delta r l w(-2)$ & $\begin{array}{c}1.138 \\
(0.424)\end{array}$ & . & $\begin{array}{l}-0.158 \\
(0.077)\end{array}$ & . & . & $\begin{array}{l}-0.269 \\
(0.111)\end{array}$ & . \\
\hline$\Delta r l(-2)$ & . & . & . & . & $\begin{array}{l}-0.211 \\
(0.071)\end{array}$ & . & . \\
\hline$\Delta r s(-2)$ & . & $\begin{array}{l}-0.199 \\
(0.089)\end{array}$ & $\begin{array}{c}0.210 \\
(0.079)\end{array}$ & . & . & $\begin{array}{l}-0.640 \\
(0.182)\end{array}$ & . \\
\hline$\Delta y(-2)$ & $\begin{array}{c}0.743 \\
(0.322)\end{array}$ & . & . & . & . & $\begin{array}{c}0.398 \\
(0.074)\end{array}$ & $\begin{array}{l}-0.138 \\
(0.032)\end{array}$ \\
\hline$\Delta n f a(-2)$ & 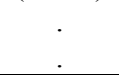 & $\begin{array}{c}0.283 \\
(0.097) \\
\end{array}$ & . & $\begin{array}{c}0.123 \\
(0.027)\end{array}$ & . & . & . \\
\hline
\end{tabular}

Table 7. Lagged endogenous terms. Standard errors in round brackets.

\section{Impulse response analysis}

Structural impulse responses provide further information on the linkages among the variables. Dynamic simulation exercises are performed. controlling for possible contemporaneous correlations among the variables, by means a short-run modeling approach based on the statistical significance of the feedback coefficient and the autoregressive parameters of the model. The reduction process gives a parsimonious model with a diagonal dispersion matrix. In this special case, the recursive scheme is not 
influenced by the ordering of the variables.

The left (right) column of Figure 1 shows the impulse response functions of $n f a$ to unitary shocks hitting all the variables of the system. The right column, instead, shows the impulse response functions of all the variables of the system to a unit shock hitting $n f a$. The graphs also include confidence intervals (at the 95\% significance level), computed following the recommendations in Benkwitz - Lütkepohl - Neumann [2] and using the bootstrap methodology proposed in Hall [10], with 1000 replications. The simulation horizon is set equal to 20 quarters.

The responses exhibit trajectories consistent with the theoretical model and the stylized facts discussed in the previous sections. The response of $n f a$ to shocks hitting domestic and world GDP and the shortterm interest rate is not statistically significant. ${ }^{8}$ A shock to the foreign longterm interest rate and to $n f a$ itself leads to NFA accumulation, conforming with portfolio stock adjustment considerations. The responses of $n f a$ to shocks hitting the domestic long-term interest rate and the real exchange rate are very weak and borderline statistically significant. ${ }^{9}$ As to the effect of shocks originating from $n f a$, the only statistically significant impulse response is that on the real exchange rate which is consistent with a permanent increase in $n f a$ leading to real exchange rate appreciation.

8 The responses of domestic and world output to shocks hitting $n f a$ seem to be related to the theoretical long-run relationship linking the two variables.

9 Even if the response of $n f a$ to a real exchange rate shock is significant at any horizon of the simulation, the deviation from the baseline path can be considered as negligible (around $0.5 \%$ in the long-run). 


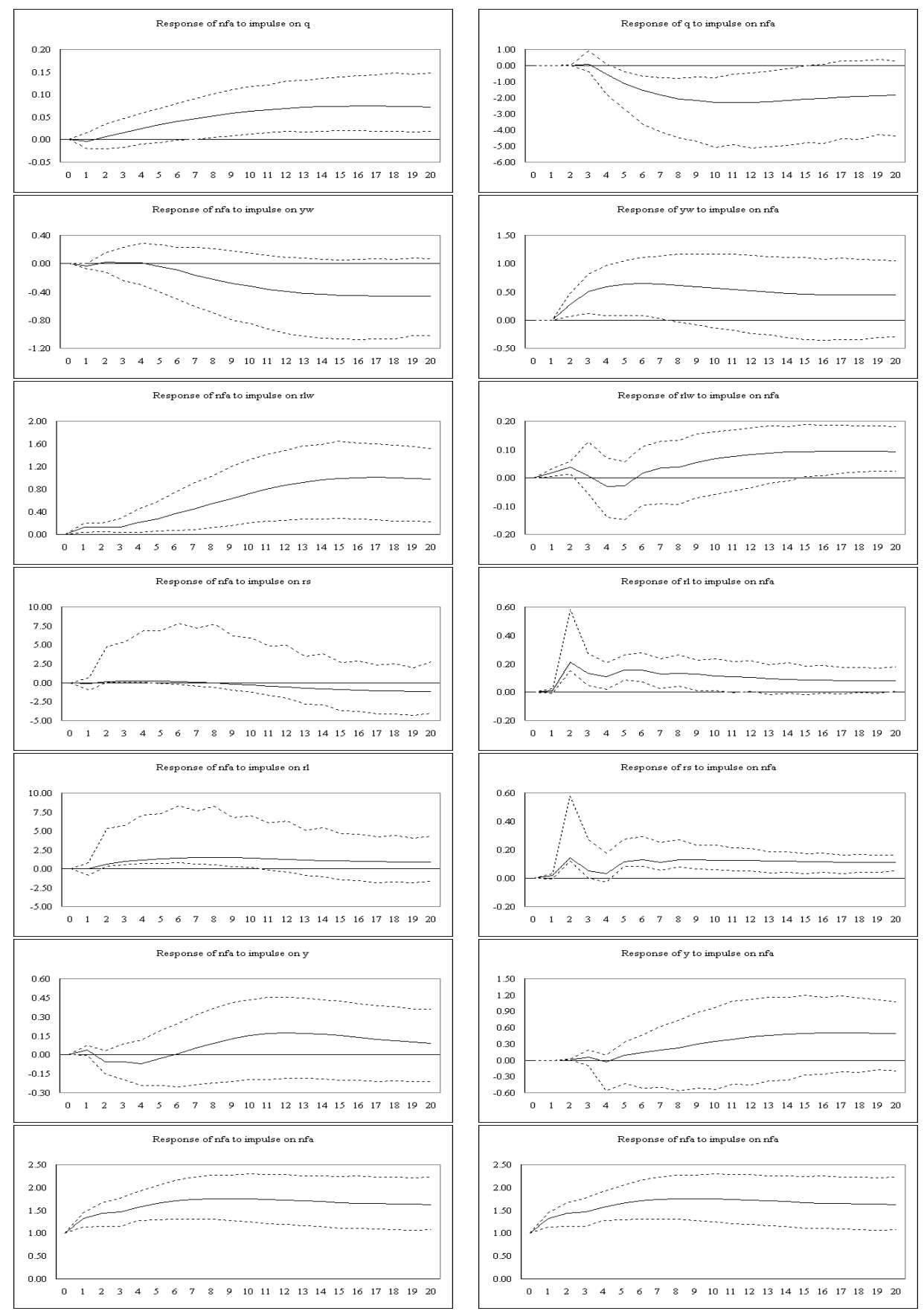

Figure 1. Impulse response analysis, structural form model. Percentage values. 


\section{Conclusions}

This paper has discussed the macroeconomics of NFA at the Euro Area level, making use of the cointegrated VAR methodology.

Our measure of NFA is broadly consistent with currently available estimates over the whole sample period. We take this as indicating that we have been using an adequate aggregative and updating procedure. The main conclusion of the paper is that, as far as Net Foreign Assets are concerned, the use of synthetic Euro area aggregate data yields a series of results consistent with economic theory. Real growth and exchange rate appreciation are both consistent with NFA accumulation. Portfolio adjustment considerations are also important.

Both these conclusions must be qualified as preliminary and subject to revision, due the lack of other empirical works on this issue. The possibility of improving upon the aggregating procedure, which we have been using, tackling the observed discrepancy between our series and those most recently calculated at the Euro area level, constitutes a first possible extension of the current research. A further extension consists in including more variables in the analysis, improving upon our preferred theoretical structure and econometric structure. 


\section{Appendix}

Elaborations have been performed using the following econometric packages: J-Multi 3.03 (SVECM model reducing process and diagnostic tests), Malcolm 2.90 (preliminary analyses), Pc-Fiml 10.3 (preliminary analyses and estimation) and SVAR 0.26 (bootstrap exercises). All seasonally unadjusted quarterly data are taken from OECD (Main Economic Indicators, CD-ROM release 2003/2) and IMF (IFS CD-Rom, March 2004) databases. Table A.1 contains further details.

\begin{tabular}{|c|c|c|c|}
\hline Series & Definition & Source & Code \\
\hline$R Y$ & Real GDP $(1995=100)$ & IFS March 04 & 99BVP/R...ZF \\
\hline$Y$ & Nominal GDP & IFS March 04 & 99B/C...ZF \\
\hline$R Y_{\mathrm{OECD}}$ & OECD Real GDP $(1995=100)$ & OECD MEI 03/2 & 000139KSA \\
\hline$P O P$ & Population & OECD MEI 03/2 & $99 Z \ldots Z F$ \\
\hline$S$ & Short-term interest rate & IFS March 04 & $60 \mathrm{~B} \ldots \mathrm{ZF}$ \\
\hline$L$ & Long-term interest rate & IFS March 04 & $61 \ldots \mathrm{ZF}$ \\
\hline$P$ & Consumer price index & IFS March 04 & $64 \ldots \mathrm{ZF}$ \\
\hline$E$ & NC-US dollar nominal exchange rate & IFS March 04 & RF ...ZF \\
\hline$D I A$ & Direct investment abroad & IFS March 04 & $78 \ldots$ BDDZF \\
\hline$P I A$ & Portfolio investment assets & IFS March 04 & $78 \ldots$ BFDZF \\
\hline$O I A$ & Other investment assets & IFS March 04 & $78 \ldots$ BHDZF \\
\hline$D I L$ & Direct investment in rep. economy & IFS March 04 & $78 \ldots$ BEDZF \\
\hline$P I L$ & Portfolio investment liabilities & IFS March 04 & $78 \ldots$ BGDZF \\
\hline OIL & Other investment liabilities & IFS March 04 & $78 \ldots$ BIDZF \\
\hline$N F A_{71}$ & Stock of NFA in 1971 & Lane and Milesi-Ferretti (2001a) & ACUMCA \\
\hline
\end{tabular}

Table A.1. Data sources. 
Synthetic aggregate data for the Euro area are calculated as weighted averages of EMU countries data. The variables are: the real effective exchange rate $(q)$, foreign real GDP per-capita ( $y w)$, foreign real long-term interest rate $(r l w)$, domestic real long-term interest rate $(r l)$,domestic real short-term interest rate $(r s)$, domestic real GDP per-capita $(y)$, and the NFA/GDP ratio ( $n f a$ ). Their construction is illustrated in Table A.2.

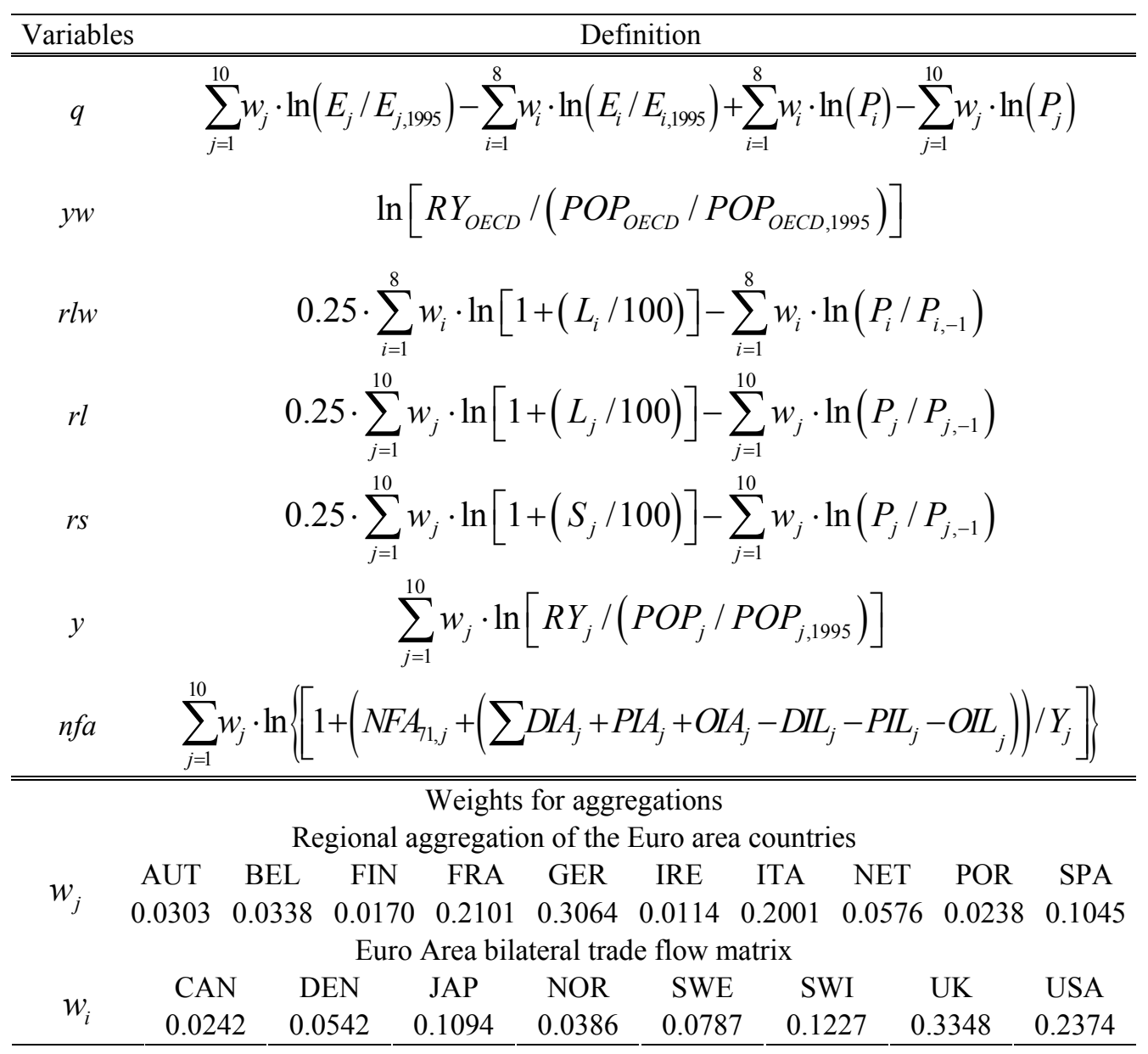

Table A.2. Construction of variables. 
Weights $w_{j}$ represent the share of national real GDP (in PPP) on the Area Euro one in the base-year (1995), whereas $w_{i}$ 's are constructed as quotas of country $i$ on total trade, defined as the sum of imports and exports, computed as an average over the period 1994-1996 (see Lewbel [21] and Pesaran - Schuermann - Weiner [26]).

As Lane - Milesi-Ferretti [19] point out, the evaluation of NFA is a difficult task involving several problems such as missing stock data (to be substituted by cumulating flows), valuation adjustments (debt reduction and forgiveness, price and exchange rate changes, mis-measurement of gross capital flows), lack of official statistics on bilateral current accounts (and their main components). In Figure A.1. we plot $n f a$ as well as the NFA/GDP ratio calculated using the same methodology as employed by Lane - MilesiFerretti [19] and Fagan - Henry - Mestre [7]. The correlation between our measure of $n f a$ and the other two is satisfactory (0.86 and 0.76 , respectively), even though some differences emerge in their evolution over time.

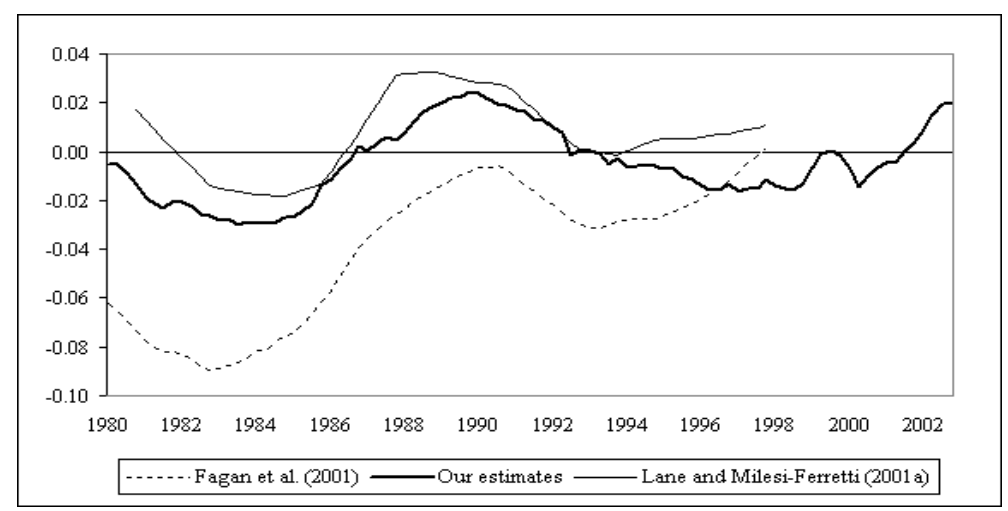

Figure A.1. NFA/GDP ratio (1980-2002). 
The behaviour of $n f a$ over the period 1980-2002 suggests that the Euro area switches from debtor to creditor status after the Plaza agreements of 1985 . The NFA/GDP ratio reaches its peak (equal to 2\%) in 1990. This is followed by a progressive deterioration of the international investment position of the Euro area which, only recently, has turned back to positive. This pattern is not fully reflected in the measure of Fagan - Henry - Mestre [7], mainly due to a different amount of the historical stock of reference. Nevertheless, such difference should not matter, because it would just reflect into a shift in the estimated intercept. 


\section{References}

[1] Agresti A. - Mojon B., «Some Stylised Facts on the Euro Area Business Cycle», in ANGELONI I. ET AL. (eds.) Monetary Transmission in the Euro Area, Cambridge University Press, 2003, Chapter 1.

[2] Benkwitz A. - LÜtKepohl H. - Neumann M., «Problems Related to Bootstrapping Impulse Responses of Autoregressive Processes», Econometric Reviews, vol. 19, n. 1, February 2000, pp. 69-103.

[3] Binder M. - Pesaran H., «Stochastic Growth Models and Their Econometric Implications», Journal of Economic Growth, vol. 4, n. 2, June 1999, pp. 139-183.

[4] BRÜggemann R. - LÜtKepohl H., «Lag Selection in Subset VAR Models with an Application to a U.S. Monetary System», in Friedmann R. ET AL. (eds.) Econometric Studies: A Festschrift in Honour of Joachim Frohn, LIT-Verlag, 2001, pp. 107-128.

[5] Bussiere M. - Choartareas G. - Driver R., «Current Accounts Net Foreign Assets and the Implications of Cyclical Factors», Eastern Economic Journal, vol. 29, n. 2, Spring 2003, pp. 269-86.

[6] Doornik J. - Hendry D., Modelling Dynamic Systems Using PcGive, Timberlake Consultants Press, 2001, vol. II.

[7] Fagan G. - Henry J. - Mestre R., «An Area-wide Model (AWM) for the Euro Area», European Central Bank, Working Paper, n. 42, January 2001.

[8] FARUQEe H. - LAXTON D., «Life Cycle Dynasties Saving: Implications for Small Open Economies», International Monetary Fund, Working Paper, n. 126, July 2000. 
[9] Fisher S. - Frenkel J., «Economic Growth and the Stages of the Balance of Payments», in HoRwich G. - SAMUELSON P. (eds.) Trade Stability and Macroeconomics, New York Academic Press, 1974, pp. 503-521.

[10] HaLl P., The Bootstrap and Edgeworth Expansion, Springer, 1992.

[11] Gagnon J., «Net Foreign Assets and Equilibrium Exchange Rates: Panel Evidence», Board of Governors of the Federal Reserve System, International Finance Discussion Paper, n. 574, December 1996.

[12] Garratt A. - Lee K. - Pesaran H. - Shin Y. (2003), «A Long-Run Structural Macroeconometric Model of the UK», Economic Journal vol. 113, n. 487, April 2003, pp. 412-455.

[13] Godley W., «Open Economy Macroeconomics Using Models of Closed Systems», The Levy Economics Institute, Working Paper, n. 281, September 1999.

[14] JOHANSEN S., «Statistical Analysis of Cointegration Vectors», Journal of Economic Dynamics and Control, vol. 12, n. 2 / 3, June / September 1988, pp. 231-254.

[15] JOHANSEN S., Likelihood-Based Inference in Cointegrated Vector Autoregressive Models Oxford University Press, 1995.

[16] Juselius K. - MACDONALd R., «International Parity Relationships between Germany and the United States: A Joint Modelling Approach», Institute of Economics, University of Copenhagen, mimeo, October 2003.

[17] KraAy A. - Ventura J., «Current Accounts in Debtor and Creditor Countries», Quarterly Journal of Economics, vol. 115, n. 4, 
November 2000, pp. 1137-1166.

[18] Lane P. - Milesi-Ferretti G., «The Transfer Problem Revisited: Net Foreign Assets and Real Exchange Rates», International Monetary Fund, Working Paper, n. 123, July 2000.

[19] Lane P. - Milesi-Ferretti G., «The External Wealth of Nations: Estimates of Foreign Assets and Liabilities for Industrial and Developing Countries», Journal of International Economics, vol. 55, n. 2, December 2001, pp. 263-294.

[20] Lane P. - Milesi-Ferretti G., «Long-term Capital Movements», National Bureau of Economic Research, Working Paper, n. 8366, July 2001.

[21] LEWBEL A., «Aggregation with log-linear models», Review of Economic Studies, vol. 59, n. 3, July 1992, pp. 635-642.

[22] Mojon B. - Peersman G., «A VAR Description of the Effects of Monetary Policy in the Individual Countries of the Euro Area» in Angeloni I. ET AL. (eds.) Monetary Transmission in the Euro Area, Cambridge University Press, 2003, Chapter 3.

[23] Mundell R., «The Great Exchange Rate controversy: Trade balances and the international monetary system» in Bergsten F. (ed.) International Adjustment and Financing: the Lessons from 1985-1991, Institute for International Economics, 1991.

[24] Pagan A., «An Examination of Some Tools for Macro-Econometric Model Building», Research School of Social Sciences, The Australian National University, mimeo, July 2003.

[25] Peersman G. - SMets F., «The Monetary Transmission Mechanism in 
the Euro Area: Evidence from VAR Analysis» in ANGELONI I. ET AL. (eds.) Monetary Transmission in the Euro Area, Cambridge University Press, 2003, Chapter 2.

[26] Pesaran H. - Schuermann T. - Weiner S., «Modelling Regional Interdependencies Using a Global Error-correcting Macroeconometric Model», Journal of Business Economics and Statistics, vol. 22, n. 2, April 2004, pp 129-162.

[27] Selaive J. - Tuesta V., «Net Foreign Assets and Imperfect Passthrough: The Consumption-Real Exchange Rate Anomaly», Board of Governors of the Federal Reserve System, International Finance Discussion Paper, n. 764, May 2003.

[28] Selaive J. - Tuesta V., «Net Foreign Assets and Imperfect Financial Integration: An Empirical Approach», Central Bank of Chile, Working Paper, n. 252, December 2003.

[29] SMets F. - Wouters R., «An Estimated Dynamic Stochastic General Equilibrium Model of the Euro Area», Journal of the European Economic Association, vol. 1, n. 5, September 2003, pp. 1123-1175. 